\title{
ASO Visual Abstract: Socioeconomic Disparities in Pancreas Cancer Resection and Survival in the Veterans Health Administration
}

Jonathan Pastrana Del Valle, MD ${ }^{1,2,3}$, Nathanael R. Fillmore, PhD ${ }^{3,6}$, George Molina, MD, MPH ${ }^{3,4}$, Mark Fairweather, $\mathrm{MD}^{3,4}$, Jiping Wang, MD, PhD ${ }^{3,4}$, Thomas E. Clancy, MD ${ }^{3,4}$, Stanley W. Ashley, MD ${ }^{3,4}$, Richard D. Urman, MD ${ }^{3,5}$, Edward E. Whang, MD ${ }^{1,3,4}$, and Jason S. Gold, MD $\mathrm{MD}^{1,3,4}$

${ }^{1}$ Surgical Service, VA Boston Healthcare System, West Roxbury, MA; ${ }^{2}$ Department of Surgery, Beth Israel Deaconess Medical Center, Boston, MA; ${ }^{3}$ Harvard Medical School, Boston, MA; ${ }^{4}$ Department of Surgery, Brigham and Women's Hospital, Boston, MA; ${ }^{5}$ Department of Anesthesiology, Perioperative and Pain Medicine, Brigham and Women's Hospital, Boston, MA; ${ }^{6}$ Massachusetts Veterans Epidemiology Research and Information Center, VA Boston Healthcare System, Jamaica Plain, MA

Disparities in surgical resection and survival for pancreatic cancer exist, even in the Veterans Health Administration (VHA), a non-fee-for-service, equal access healthcare system (https://doi.org/10.1245/s10434-021-11 250-0https://doi.org/10.1245/s10434-021-11250-0).

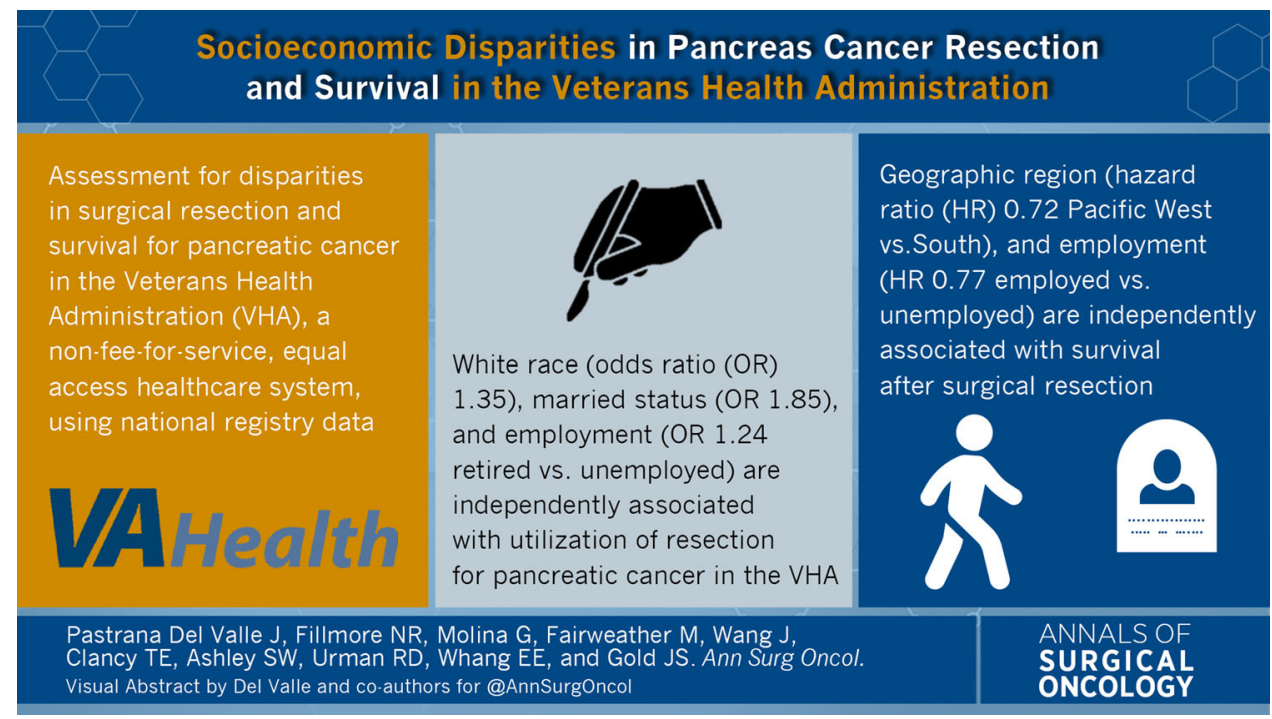

(C) Society of Surgical Oncology 2022

DICLOSURES None

J. S. Gold, MD

e-mail: jgold@bwh.harvard.edu 